\title{
MicroRNA 21 is up-regulated in adipose tissue of obese diabetic subjects
}

\author{
Valeria Guglielmi $^{\mathrm{a}, \mathrm{b}}$, Monica D’Adamo ${ }^{\mathrm{a}, \mathrm{b}}$, Rossella Menghini ${ }^{\mathrm{a}}$, Marina Cardellini ${ }^{\mathrm{a}}$, \\ Paolo Gentileschic ${ }^{\mathrm{c}}$, Massimo Federici ${ }^{\mathrm{a}}$ and Paolo Sbraccia ${ }^{\mathrm{a}, \mathrm{b}, *}$ \\ ${ }^{a}$ Department of Systems Medicine, Laboratory of Molecular Medicine, University of Rome Tor Vergata, \\ Rome, Italy \\ ${ }^{\mathrm{b}}$ Obesity Center and Internal Medicine Unit, University Hospital Policlinico Tor Vergata, Rome, Italy \\ ${ }^{\mathrm{c}}$ Department of Experimental Medicine and Surgery, University of Rome Tor Vergata, Rome, Italy
}

\begin{abstract}
We investigated miR21 expression in omental (OAT) and subcutaneous adipose tissue (SAT) from 16 obese subjects undergoing bariatric surgery. Patients were divided into two age- and BMI-matched groups according to the presence of type 2 diabetes (T2D). miR21 was not differently expressed in OAT and SAT. However, miR21 expression was two folds greater in adipose tissue in patients with T2D. Accordingly, in primary cultures of adipocytes from non diabetic overweight subjects, miR21 expression increased after 24-h exposure to high glucose and insulin. In conclusion, miR21 appears linked to insulin-resistance deterioration within its pathophysiologic progression from obesity to T2D.
\end{abstract}

Keywords: Micro RNA, miR21, type 2 diabetes, obesity, omental adipose tissue, subcutaneous adipose tissue, human adipocyte

\section{Introduction}

Obesity and type 2 diabetes with their increasing incidence have a negative impact on patients' life expectancy and quality, but also represent a significant burden on the health. Therefore, the enormous search for new therapeutic targets to obtain their control in addition to low-calorie meal plans $[1,2]$ and physical activity programs $[3,4]$ is not surprising.

In the past decade the discovery of microRNAs (miRNAs), a class of short non-coding RNAs (19-22 nucleotides) which post-transcriptionally regulate thousands of genes allowing for fine-tuning

\footnotetext{
*Corresponding author: Paolo Sbraccia, MD, PhD, Department of Systems Medicine, University of Rome "Tor Vergata", Via Montpellier 1, 00133 Rome, Italy. Tel.: +39 0672596888; Fax: +390672596890; E-mail: sbraccia@med.uniroma2.it.
}

of protein expression [5], has generated enormous research interest [6]. miRNAs can silence target genes by inhibiting messenger RNA (mRNA) translation, degrading the mRNA molecules [7], and more rarely affecting translation and gene expression in a positive manner [7, 8]. Although the true magnitude of posttranscriptional regulation by miRNAs in humans is still unknown, a widespread regulation of protein levels by miRNAs in cellular and animal models is emerging $[9,10]$.

Evidence of miRNA dysregulation has been reported in both type 2 diabetes (T2D) [11-13] and obesity [14]. Namely, miR-22 can regulate lipid/glucose homeostasis in the liver [15], mir-375 [16] and miR-9 [17] can influence insulin secretion, mir-34a can increase hormone secretion in insulinsecreting cells when exposed to palmitate [18] and the expression of several miRNAs has been reported 
to be dysregulated in adipocytes from obese individuals [19]. Since several miRNAs were found to regulate adipogenesis and adipogenic commitment of multipotent stem cells [19-21], it has been postulated that they may also account for adipocyte number and size as well as for their impaired differentiation in obesity [22].

Among 106 miRNAs detected in paired samples of subcutaneous adipose tissue (SAT) and omental adipose tissue (OAT) from obese with either normal glucose tolerance or T2D, 16 miRNAs had an expression pattern dependent on the fat depot [23], suggesting that miRNAs may contribute to specific depot features by regulating different gene targets.

miR-21, an important microRNA frequently upregulated in many types of chronic diseases [24], has been reported to be over-expressed in human obesity [25] and to enhance adipogenic differentiation through the modulation of transforming growth factor (TGF)- $\beta$ signaling [26, 27].

Since distinct adipose tissue depots [28, 29] act differentially as regional contributors to insulin resistance $[30,31]$ and to obesity complications [32, 33], we aimed to analyze the expression of miR21 in human obese OAT and SAT and its correlation with the diverse inflammatory and pro-fibrotic signature of these depots. In addition, we searched for associations between miR2 1 expression in these adipose depots and metabolic complications of obesity.

\section{Materials and methods}

Paired samples of abdominal SAT and OAT tissue were obtained from sixteen Caucasian subjects (M/F: 8/8) undergoing bariatric surgery. Real-time quantification of miRNAs was performed by using mirVana miRNA isolation kit (Ambion Inc, Austin, TX, USA), TaqMan miRNA reverse transcription kit and miRNA assay with the ABI PRISM 7000 (Applied Biosystems, Foster City, CA, USA). The U43 small nucleolar RNA (RNU43) was used as the housekeeping small RNA reference gene. For mRNA analysis, single-strand complementary DNA (cDNA) was synthesized from $1 \mu \mathrm{g}$ of total RNA isolated through TRIzol reagent (Invitrogen, Carlsbad, CA, USA) and a high-capacity cDNA archive kit. Fifty nanograms of cDNA were amplified by real-time polymerase chain reaction (RT-PCR) and normalized to $18 \mathrm{~S}$ ribosomal RNA as endogenous control. Each reaction was performed in triplicate, and analysis was performed by the $2^{-\Delta \Delta \mathrm{Ct}}$ method.
Transcripts encoding for TGF-1 $\beta$, monocyte chemotactic protein-1 (MCP-1) and tumor necrosis factor- $\alpha$ $(\mathrm{TNF}-\alpha)$ were also analyzed.

Descriptive statistics were given by means \pm SD . Comparisons (OAT versus SAT and NGT versus T2D) were determined by Mann-Whitney test for unpaired data, correlations between variables by non parametric Spearman correlation test and a $p$-value $<0.05$ based on two-sided test was considered statistically significant. Statistical analysis was performed with SPSS 19.0 software (SPSS, Chicago).

The study protocol was approved by the ethical committee of University Hospital Policlinico Tor Vergata, the investigation was conducted in accordance with the Declaration of Helsinki and all patients gave a written informed consent.

For in vitro experiments, human white subcutaneous preadipocytes (EuroClone) from overweight subjects were seeded into 12-well plates and grown in pre-adipocyte medium (EuroClone). After reaching confluence, the cells were exposed to differentiation medium (EuroClone) containing rosiglitazone, 3-isobutyl-1-methylxanthine, dexamethasone and insulin for 3 days. Cells were then fed adipocyte medium (EuroClone) replaced at 2-3-day intervals. Ten days after differentiation induction, adipocyte were lysed and endpoints examined. In different flasks, medium glucose and insulin concentrations were raised (to $20 \mathrm{mmol} / \mathrm{L}$ and $10^{4} \mathrm{lU} / \mathrm{mL}$, respectively) the last 2,6 , or 24 hours of incubation [34] as a method to mimic in vitro insulin resistance in adipocytes [35, 36].

\section{Results}

With regard to the clinical features of the subjects studied, mean age, body mass index (BMI) and waist circumference were $41.7 \pm 2.6$ years, $46.9 \mathrm{~kg} / \mathrm{m}^{2}$ and $149.7 \pm 5 \mathrm{~cm}$, respectively. Biochemical analysis revealed that 7 subjects had dyslipidemia. In addition to 4 patients with known T2D, we newly diagnosed 5 patients with T2D by performing an oral glucose tolerance test. Finally, 3 subjects were hypertensive.

As result of molecular analysis, miR21 was not differently expressed in OAT $(1.32 \pm 0.5)$ and SAT $(1.29 \pm 0.9)$ and did not correlated with the expression of the inflammatory (TNF- $\alpha$ : OAT: $1.45 \pm 0.46$; SAT: $1.01 \pm 0.32$ ), macrophage infiltration (MCP-1: OAT: $1.73 \pm 0.92$; SAT: $1.12 \pm 0.6$ ) and pro-fibrotic (TGF-1ß: OAT: $1.2 \pm 0.5$; SAT: $0.96 \pm 0.51$ ) markers analyzed. 
Table 1

Clinical characteristics of the study population in relation to the presence of type 2 diabetes

\begin{tabular}{lccc}
\hline & T2D & NGT & $p$ \\
\hline M/F $(n)$ & $6 / 3$ & $2 / 5$ & \\
Age (years) & $43.5 \pm 8$ & $39.2 \pm 10.9$ & $n s$ \\
Weight $(\mathrm{Kg})$ & $148.9 \pm 26$ & $135 \pm 39$ & $n s$ \\
BMI $\left(\mathrm{Kg} / \mathrm{m}^{2}\right.$ ) & $47.6 \pm 8.1$ & $45.9 \pm 9.9$ & $n s$ \\
Waist circumference (cm) & $148.4 \pm 7.1$ & $151.3 \pm 28$ & $n s$ \\
Fasting glucose (mg/dl) & $138 \pm 22$ & $90.2 \pm 12$ & $<0.01$ \\
Fasting insulin ( $\mu \mathrm{U} / \mathrm{ml})$ & $24.9 \pm 12.8$ & $31.6 \pm 19.9$ & $n s$ \\
HOMA-IR & $8.6 \pm 4.5$ & $7.24 \pm 4.8$ & $n s$ \\
HbA1c (mmol/mol) & $59.2 \pm 17.9$ & $35.6 \pm 9.8$ & $n s$ \\
Total Cholesterol (mg/dl) & $203 \pm 38$ & $172.6 \pm 25$ & $n s$ \\
HDL Cholesterol (mg/dl) & $36.5 \pm 14.8$ & $40.2 \pm 3.6$ & $n s$ \\
Triglycerides (mg/dl) & $264.1 \pm 173$ & $152 \pm 60$ & $n s$ \\
ALT (mg/dl) & $50.1 \pm 16.8$ & $42.6 \pm 19$ & $n s$ \\
AST (mg/dl) & $22.8 \pm 9.6$ & $31.4 \pm 14$ & $n s$ \\
$\gamma$-GT (mg/dl) & $57.3 \pm 43.8$ & $38.2 \pm 15.8$ & $n s$ \\
C-Reactive Protein (mg/l) & $9 \pm 5.1$ & $11.8 \pm 7$ & $n s$ \\
Met/GLP-1 analogues/DDPIV & $4 / 1 / 1$ & $2 / 0 / 0$ & \\
$\quad$ inhibitors (n) & & & \\
\hline
\end{tabular}

$A L T$, alanine aminotransferase; $A S T$, aspartate aminotransferase; $D D P I V$, dipeptidyl peptidase IV; $\gamma G T$, gamma-glutamyl transferase; $G L P-1$, glucagon-like peptide-1; $H D L$, high density lipoprotein; $M e t$, metformin; $N G T$, normal glucose tolerance; $T 2 D$, type 2 diabetes. Data are presented as mean \pm SD.

However, we found that miR21 expression was two times greater in SAT (T2D: $1.6 \pm 0.8$; NGT: $0.8 \pm 0.8, p<0.05)$ of subjects with T2D whose clinical characteristics are shown in Table 1. The same trend, although not statistically significant, was observed in OAT (T2D: $1.7 \pm 2.2$; NGT: $0.78 \pm 0.6$, $p=\mathrm{ns})$.

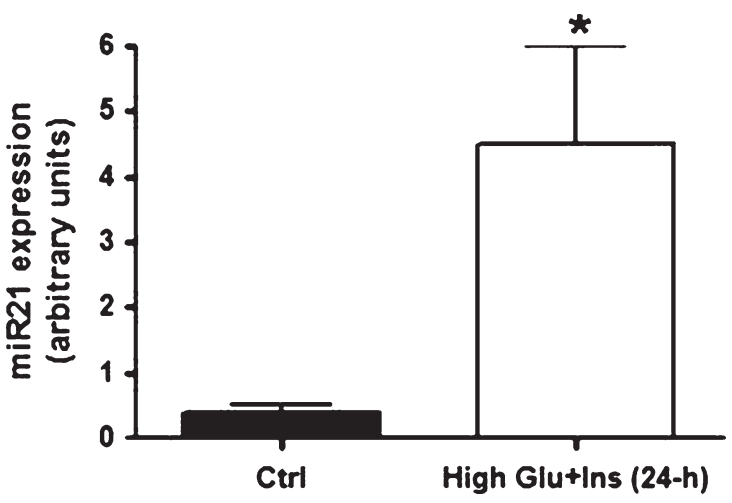

Fig. 1. miR21 expression levels in primary human adipocytes after 24-h exposure to high glucose and high insulin concentrations. miR21 expression up-regulation in mature adipocytes (at ten days after differentiation induction) after 24-hour exposure to high glucose $(20 \mathrm{mmol} / \mathrm{L})$ and high insulin $\left(10^{4} \mathrm{lU} / \mathrm{mL}\right)$ concentrations.
Since high levels of insulin and glucose are regularly detected in insulin-responsive tissues from T2D individuals, we tested whether miR21 was upregulated specifically by these conditions. In accordance with the in vivo findings, mature adipocytes (at 10 days of differentiation) treated for 24 hours with high levels of insulin and glucose displayed an upregulation of miR21 expression (Fig. 1). Incidentally, miR21 expression peaked at 3 days of differentiation (miR21: in preadipocytes: $1.035 \pm 0.37$; at 3 days of differentiation: $7.86 \pm 2.1$; at 6 days of differentiation: $2.38 \pm 1.5$; at 10 days of differentiation: $0.38 \pm 0.16)$ as previously reported [26].

\section{Discussion}

Hence, our data suggest that miR21, known to be up-regulated in human obesity, is neither differently expressed in OAT and SAT nor correlated with their distinct inflammatory and pro-fibrotic profile. However, adipose tissue expression of miR21 resulted further increased in obese affected by T2D. Indeed, the diabetic condition in vivo, as well as the persistent exposure to high insulin and glucose in vitro, seem to contribute to the up-regulation of miR21 in adipocytes. miR-21 was already reported to be up-regulated in kidneys of diabetic mice and in mesangial cell lines grown in high glucose conditions [37], in diabetic skin [38], to promote renal fibrosis in diabetic nephropathy [39-42] and to serve as a fingerprint for diabetic retinopathy [43]. At molecular level, in diabetic condition miR-21 was reported to downregulate PTEN expression increasing the downstream Akt/TORC1 activity, and to inhibit the expression of PDCD4 and SMAD7 increasing NF- $\kappa$ B signaling pathways [39, 44, 45].

Based on these findings, we might, therefore, speculate that miR21 expression is linked to the deterioration of insulin-resistance within its pathophysiologic progression from obesity to T2D [46]. Further detailed investigations are needed to assess whether miR21 plays a novel role in T2D pathogenesis.

\section{Acknowledgments}

This work was supported by a grant from the Ministero della Salute (Project n. 45/RF-2013-0235 7791). 


\section{Conflict of interests}

The authors declare no conflict of interests.

\section{References}

[1] Sacks FM, Bray GA, Carey VJ, Smith SR, Ryan DH, Anton $\mathrm{SD}$, et al. Comparison of weight-loss diets with different compositions of fat, protein, and carbohydrates. N Engl J Med. 2009;360:859-73.

[2] Lombardo M, Bellia A, Padua E, Annino G, Guglielmi V, D'Adamo M, et al. Morning meal more efficient for fat loss in a 3-month lifestyle intervention. J Am Coll Nutr. 2014;33:198-205.

[3] Bellia A, Salli M, Lombardo M, D’Adamo M, Guglielmi V, Tirabasso C, et al. Effects of whole body vibration plus diet on insulin-resistance in middle-aged obese subjects. Int J Sports Med. 2014;35:511-6.

[4] Jakicic JM, Otto AD. Physical activity considerations for the treatment and prevention of obesity. Am J Clin Nutr. 2005;82:226S-9S.

[5] Bartel DP. MicroRNAs: Target recognition and regulatory functions. Cell. 2009;136:215-33.

[6] Lagos-Quintana M, Rauhut R, Lendeckel W, Tuschl T. Identification of novel genes coding for small expressed RNAs. Science. 2001;294:853-8.

[7] Saravanan S, Thirugnanasambantham K, Hanieh H, Karikalan K, Sekar D, Rajagopalan R, et al. miRNA-24 and miRNA-466i-5p controls inflammation in rat hepatocytes. Cell Mol Immunol. 2015;12:113-5.

[8] Sekar D, Saravanan S, Karikalan K, Thirugnanasambantham $\mathrm{K}$, Lalitha P, Islam VI. Role of microRNA 21 in mesenchymal stem cell (MSC) differentiation: A powerful biomarker in MSCs derived cells. Curr Pharm Biotechnol. 2015;16:43-8.

[9] Selbach M, Schwanhausser B, Thierfelder N, Fang Z, Khanin $\mathrm{R}$, Rajewsky N. Widespread changes in protein synthesis induced by microRNAs. Nature. 2008;455:58-63.

[10] Baek D, Villen J, Shin C, Camargo FD, Gygi SP, Bartel DP. The impact of microRNAs on protein output. Nature. 2008;455:64-71.

[11] Lu J, Getz G, Miska EA, Alvarez-Saavedra E, Lamb J, Peck D, et al. MicroRNA expression profiles classify human cancers. Nature. 2005;435:834-8.

[12] Zampetaki A, Kiechl S, Drozdov I, Willeit P, Mayr U, Prokopi $\mathrm{M}$, et al. Plasma microRNA profiling reveals loss of endothelial miR-126 and other microRNAs in type 2 diabetes. Circ Res. 2010;107:810-7.

[13] D'Alessandra Y, Devanna P, Limana F, Straino S, Di Carlo A, Brambilla PG, et al. Circulating microRNAs are new and sensitive biomarkers of myocardial infarction. Eur Heart J. 2010;31:2765-73.

[14] Martinelli R, Nardelli C, Pilone V, Buonomo T, Liguori R, Castano I, et al. miR-519d overexpression is associated with human obesity. Obesity (Silver Spring). 2010;18:2170-6.

[15] Esau C, Davis S, Murray SF, Yu XX, Pandey SK, Pear M, et al. miR-122 regulation of lipid metabolism revealed by in vivo antisense targeting. Cell Metab. 2006;3:87-98.

[16] Poy MN, Eliasson L, Krutzfeldt J, Kuwajima S, Ma X, Macdonald PE, et al. A pancreatic islet-specific microRNA regulates insulin secretion. Nature. 2004;432:226-30.
[17] Plaisance V, Abderrahmani A, Perret-Menoud V, Jacquemin P, Lemaigre F, Regazzi R. MicroRNA-9 controls the expression of Granuphilin/Slp4 and the secretory response of insulin-producing cells. J Biol Chem. 2006;281:26932-42.

[18] Lovis P, Roggli E, Laybutt DR, Gattesco S, Yang JY, Widmann $\mathrm{C}$, et al. Alterations in microRNA expression contribute to fatty acid-induced pancreatic beta-cell dysfunction. Diabetes. 2008;57:2728-36.

[19] Ortega FJ, Moreno-Navarrete JM, Pardo G, Sabater M, Hummel M, Ferrer A, et al. MiRNA expression profile of human subcutaneous adipose and during adipocyte differentiation. PLoS One. 2010;5:e9022.

[20] Xie H, Lim B, Lodish HF. MicroRNAs induced during adipogenesis that accelerate fat cell development are downregulated in obesity. Diabetes. 2009;58:1050-7.

[21] Hilton C, Neville MJ, Karpe F. MicroRNAs in adipose tissue: Their role in adipogenesis and obesity. Int $\mathrm{J}$ Obes (Lond). 2013;37:325-32.

[22] Isakson P, Hammarstedt A, Gustafson B, Smith U. Impaired preadipocyte differentiation in human abdominal obesity: Role of Wnt, tumor necrosis factor-alpha, and inflammation. Diabetes. 2009;58:1550-7.

[23] Gilad S, Meiri E, Yogev Y, Benjamin S, Lebanony D, Yerushalmi N, et al. Serum microRNAs are promising novel biomarkers. PLoS One. 2008;3:e3148.

[24] Sekar D, Hairul Islam VI, Thirugnanasambantham K, Saravanan S. Relevance of miR-21 in HIV and non-HIV-related lymphomas. Tumour Biol. 2014;35:8387-93.

[25] Keller P, Gburcik V, Petrovic N, Gallagher IJ, Nedergaard J, Cannon B, et al. Gene-chip studies of adipogenesis-regulated microRNAs in mouse primary adipocytes and human obesity. BMC Endocr Disord. 2011;11:7.

[26] Kim YJ, Hwang SJ, Bae YC, Jung JS. MiR-21 regulates adipogenic differentiation through the modulation of TGF-beta signaling in mesenchymal stem cells derived from human adipose tissue. Stem Cells. 2009;27:3093-102.

[27] Lee EH, Park HJ, Jeong JH, Kim YJ, Cha DW, Kwon DK, et al. The role of asporin in mineralization of human dental pulp stem cells. J Cell Physiol. 2011;226:1676-82.

[28] Guglielmi V, Maresca L, D’Adamo M, Di Roma M, Lanzillo C, Federici M, et al. Age-related different relationships between ectopic adipose tissues and measures of central obesity in sedentary subjects. PLoS One. 2014;9:e103381.

[29] Guglielmi V, Maresca L, Lanzillo C, Marinoni GM, D’Adamo M, Di Roma M, et al. Relationship between regional fat distribution and hypertrophic cardiomyopathy phenotype. PLoS One. 2016;11:e0158892.

[30] Guglielmi V, Cardellini M, Cinti F, Corgosinho F, Cardolini I, D'Adamo M, et al. Omental adipose tissue fibrosis and insulin resistance in severe obesity. Nutr Diabetes. 2015;5:e175.

[31] Wajchenberg BL. Subcutaneous and visceral adipose tissue: Their relation to the metabolic syndrome. Endocr Rev. 2000;21:697-738.

[32] Venteclef N, Guglielmi V, Balse E, Gaborit B, Cotillard A, Atassi F, et al. Human epicardial adipose tissue induces fibrosis of the atrial myocardium through the secretion of adipo-fibrokines. Eur Heart J. 2015;36:795-805a.

[33] Guglielmi V, D’Adamo M, Bellia A, Ciotto RT, Federici M, Lauro D, et al. Iron status in obesity: An independent association with metabolic parameters and effect of weight loss. Nutr Metab Cardiovasc Dis. 2015;25:541-7. 
[34] Renstrom F, Buren J, Svensson M, Eriksson JW. Insulin resistance induced by high glucose and high insulin precedes insulin receptor substrate 1 protein depletion in human adipocytes. Metabolism. 2007;56:190-8.

[35] Thomson MJ, Williams MG, Frost SC. Development of insulin resistance in 3T3-L1 adipocytes. J Biol Chem. 1997;272:7759-64.

[36] He A, Zhu L, Gupta N, Chang Y, Fang F. Overexpression of micro ribonucleic acid 29, highly up-regulated in diabetic rats, leads to insulin resistance in 3T3-L1 adipocytes. Mol Endocrinol. 2007;21:2785-94.

[37] Fiorentino L, Cavalera M, Mavilio M, Conserva F, Menghini $\mathrm{R}$, Gesualdo L, et al. Regulation of TIMP3 in diabetic nephropathy: A role for microRNAs. Acta Diabetol. 2013;50:965-9.

[38] Madhyastha R, Madhyastha H, Nakajima Y, Omura S, Maruyama M. MicroRNA signature in diabetic wound healing: Promotive role of miR-21 in fibroblast migration. Int Wound J. 2012;9:355-61.

[39] Zhong X, Chung AC, Chen HY, Dong Y, Meng XM, Li R, et al. miR-21 is a key therapeutic target for renal injury in a mouse model of type 2 diabetes. Diabetologia. 2013;56: 663-74.

[40] Zhang Z, Peng H, Chen J, Chen X, Han F, Xu X, et al. MicroRNA-21 protects from mesangial cell proliferation induced by diabetic nephropathy in $\mathrm{db} / \mathrm{db}$ mice. FEBS Lett. 2009;583:2009-14.
[41] Sekar D, Venugopal B, Sekar P, Ramalingam K. Role of microRNA 21 in diabetes and associated/related diseases. Gene. 2016;582:14-8.

[42] McClelland AD, Herman-Edelstein M, Komers R, Jha JC, Winbanks CE, Hagiwara S, et al. miR-21 promotes renal fibrosis in diabetic nephropathy by targeting PTEN and SMAD7. Clin Sci (Lond). 2015;129:1237-49.

[43] Qing S, Yuan S, Yun C, Hui H, Mao P, Wen F, et al. Serum miRNA biomarkers serve as a fingerprint for proliferative diabetic retinopathy. Cell Physiol Biochem. 2014;34:173340.

[44] Kantharidis P, Wang B, Carew RM, Lan HY. Diabetes complications: The microRNA perspective. Diabetes. 2011;60:1832-7.

[45] Dey N, Das F, Mariappan MM, Mandal CC, GhoshChoudhury N, Kasinath BS, et al. MicroRNA-21 orchestrates high glucose-induced signals to TOR complex 1, resulting in renal cell pathology in diabetes. J Biol Chem. 2011;286:25586-603.

[46] Buren J, Liu HX, Lauritz J, Eriksson JW. High glucose and insulin in combination cause insulin receptor substrate1 and -2 depletion and protein kinase $\mathrm{B}$ desensitisation in primary cultured rat adipocytes: Possible implications for insulin resistance in type 2 diabetes. Eur J Endocrinol. 2003; 148:157-67. 